\title{
Comparative Catalytic Activity of Metal-Containing Catalysts of Different Nature in the Liquid-Phase Aerobic Oxidation of Ethylbenzene
}

\author{
Vagif Abbasov, Eldar Zeynalov* and Narmina Abdullayeva \\ National Academy of Sciences of Azerbaijan, Institute of Petrochemical Processes, Khojaly Aven. 30, AZ1025 Baku, \\ Azerbaijan
}

\begin{abstract}
The article describes an impact of metal-containing compounds - carbon nanofiber of platelet type, ferrocene and naphthenate $\mathrm{Co}$ on the aerobic oxidation of ethylbenzene. It has been established that all types of the added compounds reveal significant catalytic activity in the oxidation of ethylbenzene and may be ordered as: ferrocene $>$ naphthenate $\mathrm{Co} \geq$ carbon nanofiber.

The authors guess that the results obtained are helpful to design new catalytic oxidation process profile of diesel fraction rich by aromatics.
\end{abstract}

Keywords: Ethylbenzene, liquid-phase oxidation of hydrocarbons, metal-containing carbon nanofiber, oxidation catalysts, oxidation rate, tetraline.

\section{INTRODUCTION}

The processes of liquid-phase aerobic oxidation of hydrocarbons have a great importance for the materials science and engineering. From the scientific point of view these are essential scientific lines making influential contribution to understanding the mechanism of natural and synthetic processes involving carbon and oxygen [1-3], from the side of practical applications - there are the operating industrial processes manufacturing the main part of the world chemical production $[4,5]$.

Catalysis of hydrocarbons oxidation is a large subsection of liquid-phase oxidation which is widely highlighted in literature [6-10]. The analysis of recent publications shows that investigators see the development not only in selection of new types of effective catalytic systems, but they intensively apply untraditional approaches which employ cavitation, magnetic, microwave and ultrasonic techniques for processing of solid compact catalysts or direct impact on a process of chemical transformation. The use of advantages of a scale factor also became very topical to the application of nano-catalysts.

The present paper describes kinetic aspects of oxidation of ethylbenzene in the presence of carbon nanofiber of a platelet type (CNF-PL), ferrocene and naphthenate Co. The choice of catalysts was stimulated by the comprehensive searching of a new simple catalyst to provide the oxidation of oil aromatic hydrocarbons in a medium which is free of acidic components.

The CNF-PL involved contains 5 wt.\% of $\mathrm{Fe}$ and we supposed that combination of nano-dimensional carbon

*Address correspondence to this author at the National Academy of Sciences of Azerbaijan, Institute of Petrochemical Processes, Khojaly Aven. 30, AZ1025 Baku, Azerbaijan; Tel: +99412 4902476;

Fax:+99412 4903520; E-mail: zeynalov_2000@yahoo.com moiety and the metal of variable valency should lead theoretically to significant catalytic effects.

"One of the most important applications for ferrocene is its use as an additive for promoting the smokeless combustion of fuels. Comparatively low concentrations of ferrocene have a marked effect upon carbon formation, and appear to catalyze the oxidation of soot" [11], which consists predominantly of aromatic structures. Therefore it has been interesting to involve ferrocene for oxidation of the alkyl aromatic hydrocarbon.

"Cobalt naphthenate is commonly used in various catalytic systems for organic synthesis. These coordination complexes are widely used as oil drying agents to afford the autoxidative crosslinking. Metal naphthenates are not well defined in conventional chemical sense that they are mixtures. They are widely employed catalysts because they are soluble in the nonpolar substrates, such as the alkyd resins or linseed oil" and are widely used for synthesis of artificial naphthenic acids. "A second virtue of these species is their low cost" [12-16].

The ethylbenzene oxidation may be considered as a process simulating the oxidation of aromatic compounds of a diesel oil fraction. "As diesel fuel gets much older, a fine sediment and gum forms in the diesel brought about by the reaction of diesel components with oxygen from the air" [17]. On the other side the diesel aerobic oxidation designed reasonably can afford many industrially valuable oxygen containing compounds. This goal requires a suitable catalytic system. Thus, the diesel fraction oxidation matter and ways of its realization is of considerable importance for petrochemistry and oil refining.

\section{EXPERIMENTAL PROCEDURES}

The employed ethylbenzene was 98\% pure («Aldrich»). The oxidation of ethylbenzene was conducted at temperature $100^{\circ} \mathrm{C}$ and oxygen pressure $\mathrm{P}_{\mathrm{O} 2}=20 \kappa \mathrm{Pa}$ (air).

The potential catalytic admixtures were: 
1. Carbon nanofiber CNF-PL (platelet structure) manufactured by German Future Carbon $\mathrm{GmbH}$ with average diameter of particles $=100-250 \mathrm{~nm}$; length $=$ $1-5 \mu \mathrm{m}$, BET-surface $\sim 120 \mathrm{~m}^{2} / \mathrm{g}$, content of the metal (Fe) $\leq 5$ wt. $\%$ (Fig. 1).

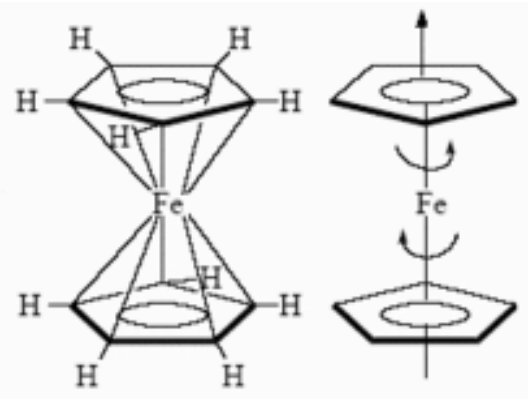

Fig. (1). Morphology and structure of carbon nanofiber of a platelet type (CNF-PL).

2. Ferrocene $\mathrm{C}_{10} \mathrm{H}_{10} \mathrm{Fe}$ was donated by the Germany Sigma-Aldrich Chemie $\mathrm{GmbH}$. The calculated Fe content is about $30 \%$.

3. Naphthenate $\mathrm{Co}\left[\mathrm{Co}(\mathrm{RCOO})_{2}\right]$ was synthesized in the laboratory by the following interaction:

$\mathrm{RCOOH}+\mathrm{NaOH} \rightarrow \mathrm{RCOONa}+\mathrm{H}_{2} \mathrm{O}$

$2 \mathrm{RCOONa}+\mathrm{CoSO}_{4} \rightarrow \mathrm{Co}(\mathrm{RCOO})_{2}+\mathrm{Na}_{2} \mathrm{SO}_{4}$

Here: $\mathrm{RCOOH}$ is distilled naturally occurring petroleum acids with acidity index - $250 \mathrm{mg} \mathrm{KOH} / \mathrm{g}$ and molecular weight $\mathrm{MW} \approx 220 \mathrm{~g} / \mathrm{mole}$; Sodium hydroxide - $10 \%$ aqueous solution; RCOONa - sodium salt of the petroleum acid.

The saponification of the natural petroleum acid by $10 \%$ of the sodium hydroxide aqueous solution was carried out at temperatures $60-80^{\circ} \mathrm{C}$ and at continuous stirring. The reaction is considered to be completed when the value of the acid number of the reaction mix reaches 3-5 $\mathrm{mg} \mathrm{KOH} / \mathrm{mg}$.

Then the mixture is diluted with the solvents (white spirit + butanol), and cobalt sulphate is introduced inward. The reaction is conducted at $70-80^{\circ} \mathrm{C}$ for $1.5-2$ hours with uninterrupted stirring. The exchange reaction proceeds according to the above stated pathway. The cobalt salt of the petroleum acids is left in hydrocarbon phase whereas the sodium sulphate are directed to an aqueous phase. In order to enlarge the moiety of the aqueous phase hot water $\left(70-80^{\circ} \mathrm{C}\right)$ is further added. The stirring is stopped and the mix is left for sedimentation for 24 hours.

Average molecular weight of $\mathrm{Co}(\mathrm{RCOO})_{2}$ obtained is $=$ 500 , the cobalt content is $10 \%$.

Since the oxidation is promoted mostly by metal moiety of a catalyst [1,2,9] the dosage of the additives in experiments was arranged appropriately.

The oxidation of ethylbenzene was conducted in the absence and presence of the catalysts. "The rate of oxidation was evaluated from the amount of oxygen consumed, which was measured volumetrically with the simple equipment" as shown in Fig. (2) and described in [18-21]. Oxidation rate values were calculated from slopes of kinetic curves of oxygen consumption.

\section{RESULTS AND DISCUSSIONS}

The results of kinetic experiments are exemplified in Fig. (3), where profiles of kinetic dependences of the oxygen uptake for ethylbenzene oxidation in the presence of CNF-PL, ferrocene and naphthenate Co are shown. It should be noted that ethylbenzene without catalyst at this condition is not oxidized - there is not marked and measurable oxygen uptake.

The experimental data show that all samples, each containing 5 wt.\% of the metals accelerate the model oxidation. However the acceleration degree and profile of the kinetic curves are different. Oxidation rates values are given in Table $\mathbf{1}$.

It is well-known that temperature $100^{\circ} \mathrm{C}$ is lowest heat point for hydroperoxide's thermal decomposition in oxidation of hydrocarbons $[1,2]$. Therefore the activity of

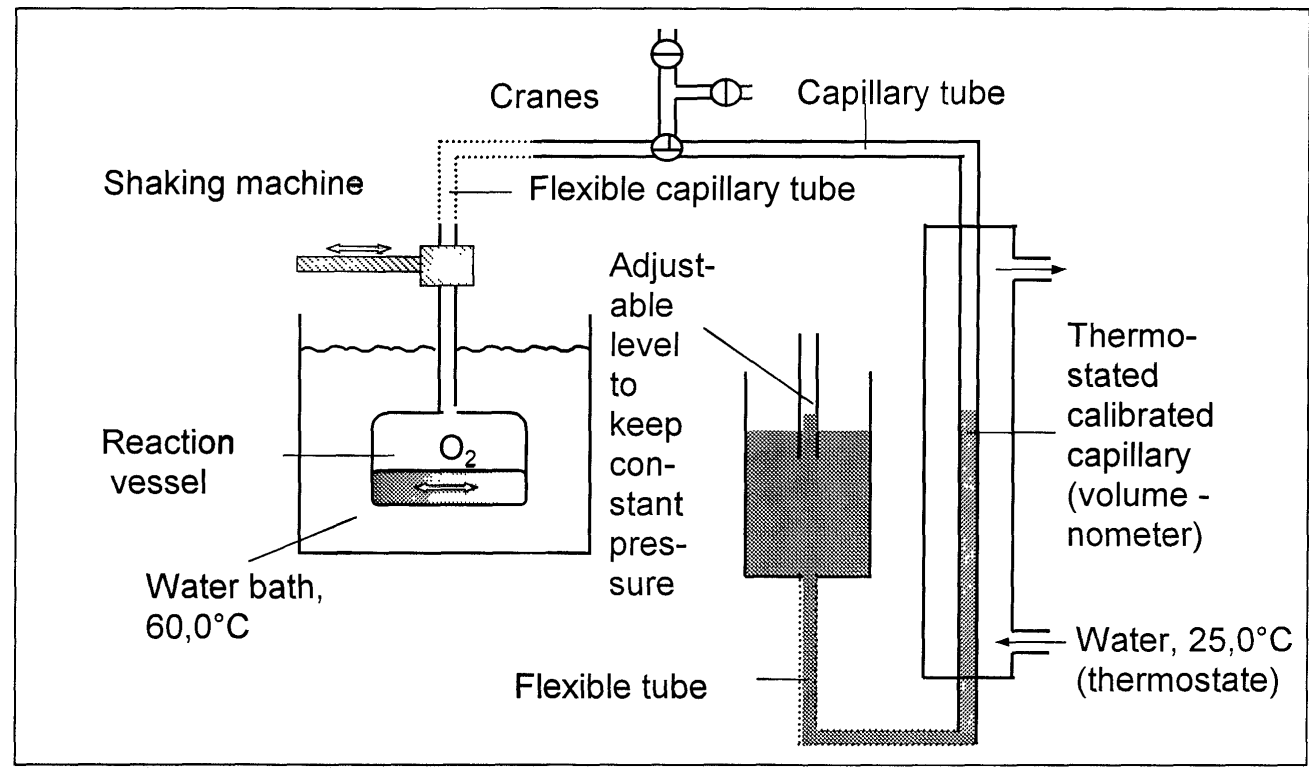

Fig. (2). Schematic diagram of measuring equipment for oxygen uptake at constant pressure [21]. 


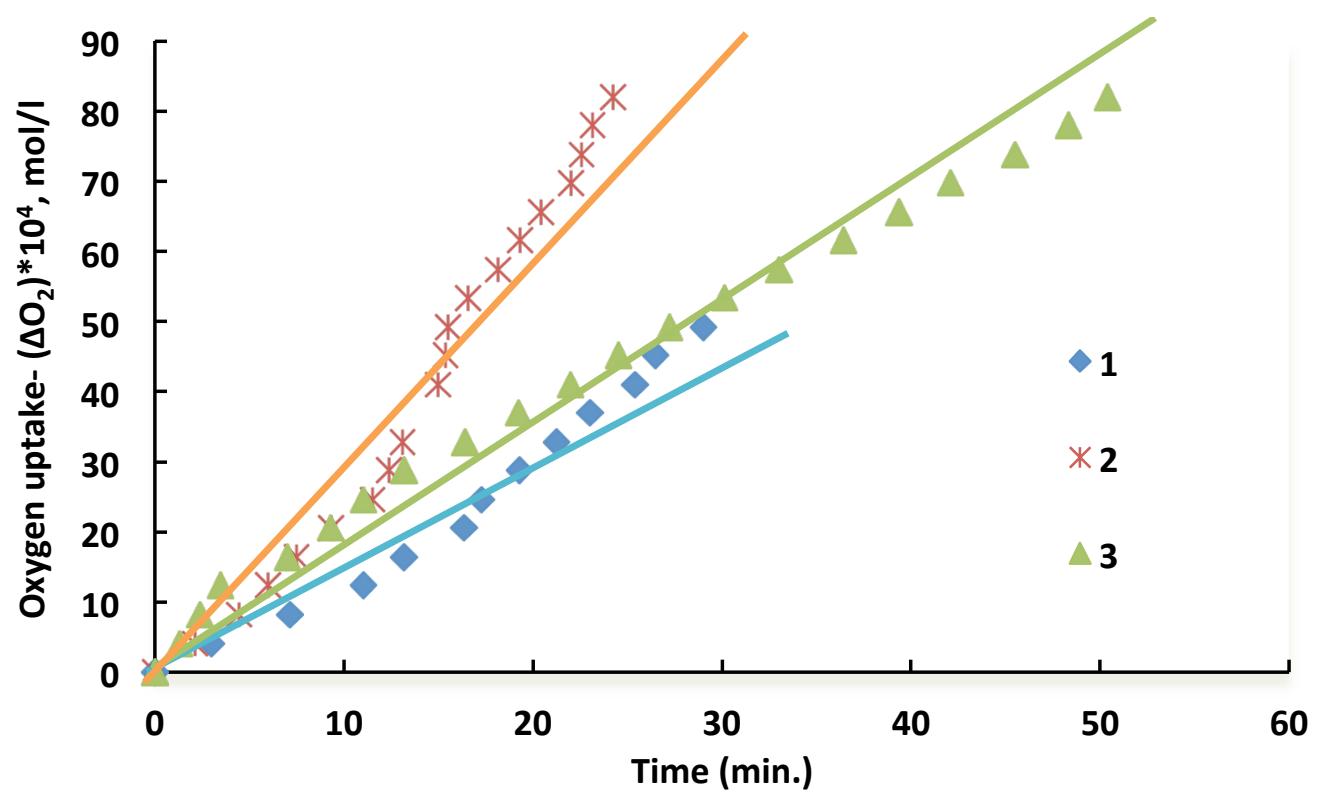

Fig. (3). Kinetic lines of oxygen oxygen-uptake during aerobic oxidation of ethylbenzene in the presence of the compounds: carbon nanofiber of platelet-type (CNF-PL) (1); ferrocene (2); naphthenate Co (3). Reaction mixture volume $5 \mathrm{ml}$, oxygen pressure: $\mathrm{Po}_{2}=20 \mathrm{kPa}$ (air), temperature $100^{\circ} \mathrm{C} .[\mathrm{CNF}-\mathrm{PL}]=20 \mathrm{~g} / 1(\mathrm{Fe}=1 \mathrm{~g} / \mathrm{l}) ;[$ Ferrocene $]=3.2 \mathrm{~g} / 1(\mathrm{Fe}=1 \mathrm{~g} / \mathrm{l})$; [Naphthenate $\left.\mathrm{Co}\right]=10 \mathrm{~g} / 1(\mathrm{Co}=1 \mathrm{~g} / 1)$.

Table 1. The data on the kinetics of oxygen uptake in the liquid phase oxidation of ethylbenzene. Reaction mixture volume: 5 ml, oxygen pressure: $\mathrm{PO}_{2}=20 \mathrm{kPa}$ (air), temperature $=100^{\circ} \mathrm{C}$. Content of metals in the oxidizing hydrocarbon $=1 \mathrm{~g} / \mathrm{l}$.

\begin{tabular}{|c|c|c|}
\hline Type of Catalyst (A Metal Content, wt.\%) & Oxidation Rate, $\mathbf{W O}_{\mathbf{2}}, \mathbf{~ m m}^{\mathbf{3}} \mathbf{O}_{\mathbf{2}} / \mathbf{m i n}$ & Oxidation Rate, $\mathbf{W O}_{\mathbf{2}} \times \mathbf{1 0}^{\mathbf{6}}, \mathbf{m o l} \mathbf{O}_{\mathbf{2}} / \mathbf{l} \mathbf{s}$ \\
\hline \hline without & 0 & 0 \\
\hline Carbon nanofiber, CNF-PL (Fe $=5$ wt.\%) & $20 \pm 4.0$ & $2.7 \pm 0.5$ \\
\hline Ferrocene (Fe = 30 wt.\%) & $42 \pm 8.0$ & $5.7 \pm 1.0$ \\
\hline Naphthenate Co (Co = 10 wt.\%) & $22 \pm 2.0$ & $3.0 \pm 0.4$ \\
\hline
\end{tabular}

the catalysts observed can serve as indicator of its applicability to the oxidation of alkyl aromatic hydrocarbons. The ferrocene displays the highest activity, CNF-PL and naphthenate Co have approximately equal catalytic activity. It is interesting to note that the profiles of kinetic curves for Fe-containing catalysts are autocatalytic while for the Co-naphthenate the oxygen uptake occurs with steady rate.

Analysis of recent literature material has shown that ethylbenzene can also be oxidized: 1) by the blended cobaltmanganese catalyst [22]; 2) with hydrogen peroxide and molecular oxygen catalyzed by cobalt and bromide ions in acetic acid as solvent [23]. However, in the first case there is some obstacles connected with the catalyst precipitation, in the latter work the acidic medium exists that is undesirable for the industrial processes.

\section{CONCLUSION}

1. It has been revealed for the first time that aerobic oxidation of ethylbenzene may be accelerated by the addition of the metal-containing compounds: Febearing carbon nanofiber of platelet type (heterogeneous catalysis), ferrocene and Co salt of indigenous petroleum acid (homogeneous catalysis).

2. In the presence of Fe-containing compounds (CNFPL, ferrocene) the autotocatalytic progress of the reaction is observed while in the presence of naphthenate Co the oxidation onset is occurred steadily.

3. Ferrocene exhibits the highest catalytic activity in comparison with others.

4. The catalysts tested are affordable and may be recommended for the aerobic oxidation of alkyl aromatic hydrocarbons.

\section{CONFLICT OF INTEREST}

The authors confirm that this article content has no conflict of interest.

\section{ACKNOWLEDGEMENTS}

Declared none.

\section{REFERENCES}

[1] Emanuel NM, Denisov ET, Maizus ZK, Eds. Liquid-phase oxidation of hydrocarbon. Plenum Press: New York 1967.

[2] Scott G, Ed. Atmospheric oxidation and antioxidants. $2^{\text {nd }}$ ed. Elsevier: New-York - Amsterdam 1993.

[3] Ishii Y, Sakaguchi S, Iwahama T. Innovation of hydrocarbon oxidation with molecular oxygen and related reactions. Adv Synth Catal 2001; 343(5): 393-427.

[4] Suresh AK, Sharma MM, Sridhar T. Engineering aspects of industrial liquid-phase air oxidation of hydrocarbons. Ind Eng Chem Res 2000; 39(11): 3958-97.

[5] Litvintsev I. Oxidation processes in industrial organic chemistry. Soros Edu J 2004; 8(1): 24-31. 
[6] Yamaguchi K, Mizuno N. Heterogeneously catalyzed liquid-phase oxidation of alkanes and alcohols with molecular oxygen. New J Chem 2002; 26(8): 972-4.

[7] Papahagi L, Ponoran I, Parausanu V. N-Alkanes liquid-phase oxidation with molecular oxygen in the presence of some synergetic catalysts mixture. Revista de Chimie 1994; 45(12): 1057-61.

[8] Papahagi L, Ponoran I, Parausanu V. Liquid-phase oxidation of n-alkanes with molecular-oxygen in the presence of some complex catalysts. Revista de Chimie 1994; 45(5): 379-84.

[9] Carter MI. Catalytic air oxidation of ambient temperature hydrocarbons. J Mol Catal A Chem 2003; 200: 191-203.

[10] Hermans I, Spier E, Neuenschwander U, et al. Selective oxidation catalysis: opportunities and challenges. Top Catal 2009; 52(9): 1162-74

[11] Rausch M, Vogel M, Rosenberg H. Ferrocene: a novel organometallic compound. J Chem Edu 1957; 34(6): 268-72.

[12] http://en.wikipedia.org/wiki/Cobalt(II) naphthenate

[13] Zeynalov BK, Ed. Synthetic naphthenic acids. Baku: Elm 1996.

[14] Mal'kovskii PA, Zainullov MR, Minkhairov MF, Gaifullin AA, Solodova NL. Oxidation of naphthenic hydrocarbons of senomanion condensate. Petrol Chem 2003; 43(1): 46-9.

[15] Cirinnova V, Miljkovic D, Repic S. Synthesis of petroleum acids by the catalytic oxidation of medium distillates of naphthenic crude oil. Petrol Chem 1992; 32(6): 448-53.

[16] Opris I, Tofan C, Cigolea V. Synthesis naphthenic acids obtained by a heavy oil catalytic-oxidation. Revista de Chemie 1995; 46(7): 701-2.
[17] http://www.fdbnetwork.com

[18] Zeynalov EB, Allen NS, Salmanova NI. Radical scavenging efficiency of different fullerenes C60 - C70 and fullerene soot. Polym Degrad Stab 2009; 94(8): 1183-9.

[19] Zeynalov EB, Vasnetsova OA, Eds. Kinetic screening of inhibitors of radical reactions. Baku: Elm 1993.

[20] Zeinalov EB, Schroeder HF, Bahr H, Eds. Determination of phenolic antioxidant stabilizers in PP and HDPE by means of an oxidative model reaction. Paper 3. In Proceedings of the $6^{\text {th }}$ International Plastics Additivies and Modifiers Conference Addcon World 2000; Basel: Switzerland 2000.

[21] Zeynalov EB, Allen NS. Simultaneous determination of the content and activity of sterically hindered phenolic and amine stabilizers by means of an oxidative model reaction. Polym Degrad Stab 2004; 85(2): 847-53.

[22] Bukharkina TV, Verzhichinskaya SV, Makarov ME, Shulyaka SE. Kinetics of oxidation of ethylbenzene by oxygen in the presence of homogeneous cobalt-manganese catalyst. Proceedings of the $4^{\text {th }}$ Conference "Molecular Design of Catalysts and Catalysis in Processes of Hydrocarbons Processing and Polymerization" dedicated to the memory of Prof. Yu. I. Ermakov: Novosibirsk 2010; pp. 140-1.

[23] Gutmann B, Elsner P, Roberge D, Kappe O. Homogeneous liquidphase oxidation of ethylbenzene to acetophenone in continuous mode. ACS Catal 2013; 3(2): 2669-76.

(C) Abbasov et al.; Licensee Bentham Open.

This is an open access article licensed under the terms of the Creative Commons Attribution Non-Commercial License (http://creativecommons.org/licenses/by-nc/3.0/) which permits unrestricted, non-commercial use, distribution and reproduction in any medium, provided the work is properly cited. 